Comment

\title{
The Catch-22 of Pharmacy Practice in Pakistan's Pharmacy Education
}

Atta Abbas ${ }^{1,2}$

1 Department of Pharmacy, Health and Well Being, Faculty of Applied Sciences, University of Sunderland, England, SR1 3SD, UK; E-Mail: bg33bd@student.sunderland.ac.uk; Tel.: +44-743-668-8150

2 Department of Pharmacy Practice, Faculty of Pharmacy, Ziauddin University, Karachi, 75600, Pakistan; Tel.: +92-321-264-3077

Received: 30 March 2014; in revised form: 15 June 2014 / Accepted: 24 June 2014 /

Published: 4 July 2014

\begin{abstract}
New developments in the pharmacy education structure in Pakistan led to the formation of a separate department grouping high specialized services/subjects. However, inadequate planning has exposed a vacuity, as the educational authorities failed to develop a workforce before creating the specialized department. As a result, this vacuum is on the verge of being impinged by pharmacy professionals specialized in entirely different domains which would be detrimental to the future prospects of the development of pharmacy practice in Pakistan.
\end{abstract}

Keywords: pharmacy; pharmacy education; Pakistan

\section{Introduction}

Recently the pharmaceutical academic environment of Pakistan braced itself to witness the birth of a separate domain for different specialties in the practice of pharmacy. This concept was realized and refined by the Higher Education Commission of Pakistan HEC [1] and Pharmacy Council of Pakistan PCP [2] and consists of a separate academic department covering a combination of different practicing areas, ranging from highly specialized patient health care oriented areas to drug promotion and marketing. The application and practices of pharmacy drugs laws as well as arithmetic, statistics used in pharmacy were all grouped in a single domain: the department of pharmacy practice [3,4]. However, the concept is in jeopardy and at risk of being encroached by other domains of pharmacy since it is a novel concept that not many people are aware of and a lucrative area. The authorities have failed to realize that 
the unavailability of the professionally trained and qualified specialists in the country would lead to an availability crisis of professionals in the aforementioned domain and now, with the establishment of this department, highly specialized practice subjects, such as clinical pharmacy and hospital pharmacy for instance, are left unattended and are viewed as an open slot for other pharmacy professionals specialized in an entirely different domain to encroach and occupy.

Since there is no pharmacy institute in Pakistan at present with a fully-fledged clinical pharmacy specialization program, it is evident that, apart from those who are specialized from abroad, there is not a single qualified trained individual in this domain. Since its inception, the clinical pharmacy and pharmacy practice department in general has witnessed an influx of professionals from different departments specialized in totally different fields within the pharmacy academia, taking advantage of the situation. In a recent study it was evident that the professionals in the pharmacy practice department, particularly in areas of clinical pharmacy and hospital, perceive foreign qualified clinical and hospital pharmacists as a potential threat to their existence in the department, which is evident as they are not specialized and hence cannot justify holding their positions $[5,6]$.

\section{Discussion}

Looking at this from a regional context, for instance China, the initiative was taken up by the educational authority i.e., Ministry of Education which focused on the development of a workforce for the outlined purpose with novel initiatives such as professional development by non-degree teaching and offering degrees in specialties within the clinical pharmacy discipline. This is similar to the set up in the United States [7]. However, Pakistan has found itself in difficulties and, in the context of promoting quality education in Pakistan, this trend of encroachment is not helpful as it will also lead to inadequate teaching of the specialized subjects to students with knowledge not being transferred as it should be [8]. This malpractice has also led to detrimental consequences in the overall health practice of Pakistan as the majority of health care professionals observed in a study seemed unsatisfied with the clinical pharmacist and noted ineptitude and poor knowledge as being the core issues [5,9]. This situation is a wakeup call for the Higher Education Commission of Pakistan HEC which, similar to other governing bodies in Pakistan, has been exposed for having inadequately planned this new department.

\section{Conclusions}

Qualified foreign clinical pharmacists present in the country must be brought together on a single platform to set up a board or committee in order to guide the Higher Education Commission HEC in training of pharmacy professionals in the aforementioned specialized domains in pharmacy, awarding certain institutes of Pakistan, as a first step, to develop a workforce. Secondly, the authorities have to enforce strict regulations regarding encroachment of the department from other pharmacy professionals, so that the department can be run by meritorious specialized professionals. It is a fundamental fact that a teacher must be qualified in the subject being taught. We need to implement this concept within the pharmacy practice otherwise valuable time is wasted. 


\section{Conflicts of Interest}

The author declares no conflict of interest.

\section{References}

1. Higher Education Commission of Pakistan. HEC. Available online: http://www.hec.gov.pk/ Pages/HECMain.aspx (accessed on 19 January 2014).

2. Pharmacy Council of Pakistan. Available online: http://www.pharmacycouncil.org.pk/ (accessed on 1 February 2014).

3. Establishment of five departments in pharmacy teaching institutes/ schools/ faculties; approved by National Curriculum Revision Committee (NCRC), HEC, Pakistan..Pharmaceutical Review. Available online: http://pharmareview.wordpress.com/2011/10/17/establishment-of-fivedepartments-in-pharmacy-teaching-institutions-schools-faculties-approved-by-national-curriculu m-revision-committee-ncrc-hec-pakistan/ (accessed on 1 July 2014).

4. The Higher Education Commission of Pakistan HEC. Curriculum of Doctor of Pharmacy. Available online: http://www.hec.gov.pk/InsideHEC/Divisions/AECA/CurriculumRevision/ Documents/Draft-Pharmacy-2011.pdf (accessed on 24 January 2014)

5. Abbas, A.; McGarry, K. The dilemma of clinical pharmacy practice in Pakistan. 2013, unpublished work.

6. Adnan, S.; Tanwir, S.; Abbas, A.; Beg, A.E.; Sabah, A.; Safdar, H.; Moin, M.; Fatima, R.; Mobeen, K.; Shams, M. Perception of physicians regarding patient counselling by pharmacist: A blend of quantitative and qualitative insight. Int. J. Pharm. Ther. 2014, 5, 117-121.

7. Ryan, M.; Shao, H.; Yang, L.; Nie, X.-Y.; Zhai, S.-D.; Shi, W.; Lubawy, W.C. Clinical Pharmacy Education in China. Am. J. Pharm. Ed. 2008, 72, 1-7.

8. Abbas, A.; McGarry, K. The significance of qualified clinical pharmacists in teaching clinical pharmacy subjects in pharmacy institutes of Pakistan. 2013, unpublished work.

9. Abbas, A.; McGarry, K. Polypharmacy in Pakistan. Perceptions of Health Care Professionals (HCPs) Regarding Pharmacist Interventions to Reduce Polypharmacy in Pakistan. Master's Thesis, University of Sunderland, UK, 2013.

(C) 2014 by the authors; licensee MDPI, Basel, Switzerland. This article is an open access article distributed under the terms and conditions of the Creative Commons Attribution license 98 (http://creativecommons.org/licenses/by/3.0/). 